\title{
Network concentration and airport congestion in a post de- regulation context: a case study of Brazil 2000-2010
}

\author{
Alessandro V. M. Oliveira. Aeronautics Institute of Technology, Brazil. \\ Email: avmoliveira@gmail.com \\ Gui Lohmann. Griffith University, Australia. \\ Email: g.lohmann@griffith.edu.au , $\left(^{*}\right)$ corresponding author \\ Tiago G. Costa. Virtus BR Partners, Brazil. \\ Email: tiagofgc@ig.com.br.
}

\section{Abstract}

This paper empirically investigates the main drivers of airline network concentration in an air transport market subject to rapid growth. We consider the Brazilian air transport industry of the 2000s, in which network concentration rapidly increased and was followed by a period of massive flight delays and cancelations, which resulted in the "big blackout" of 2006-2007. We develop an econometric model of network concentration, accounting for demand, cost and competition variables that may affect the propensity of carriers to concentrate flights and passenger connections on a few airports of a network. The main focus of the paper is on the relation between networks leading to the problems of the blackout episode. We investigate the dynamic pattern of the evolution of concentration before and after the abnormal period of operations and find that concentration began to rise at least six quarters before, and persisted at a high level until two quarters after the blackout - and then plunged steeply toward the end of the decade. We believe that our analysis contributes to an improved understanding of the behavior of air transport systems subject to network concentration and congestion. With respect to methodology, we suggest and employ the use of alternative measures of network concentration to check the robustness and validity of our results. 
Keywords: air transport; network concentration; econometrics; Brazil; HerfindahlHirschman Index (HHI). 
- We develop an econometric model of air transport network concentration.

- We investigate the dynamic pattern of the evolution of concentration.

- The highlight of this research is the Brazilian domestic "blackout" period 2006-7.

- Concentration raised six quarters prior and persisted two quarters after the "blackout".

- We use alternative measures of network concentration for robustness and validity. 


\title{
Network concentration and airport congestion in a post de- regulation context: a case study of Brazil 2000-2010
}

\begin{abstract}
This paper empirically investigates the main drivers of airline network concentration in an air transport market subject to rapid growth. We consider the Brazilian air transport industry of the 2000s, in which network concentration rapidly increased and was followed by a period of massive flight delays and cancelations, which resulted in the "big blackout" of 2006-2007. We develop an econometric model of network concentration, accounting for demand, cost and competition variables that may affect the propensity of carriers to concentrate flights and passenger connections on a few airports of a network. The main focus of the paper is on the relation between networks leading to the problems of the blackout episode. We investigate the dynamic pattern of the evolution of concentration before and after the abnormal period of operations and find that concentration began to rise at least six quarters before, and persisted at a high level until two quarters after the blackout - and then plunged steeply toward the end of the decade. We believe that our analysis contributes to an improved understanding of the behavior of air transport systems subject to network concentration and congestion. With respect to methodology, we suggest and employ the use of alternative measures of network concentration to check the robustness and validity of our results.
\end{abstract}

Keywords: air transport; network concentration; econometrics; Brazil; HerfindahlHirschman Index (HHI). 


\section{Introduction}

The Brazilian air transport industry has been subject to major transformations since Brazil's economic deregulation of the 1990s and early 2000s. One of the major changes in the short run was increased competition and a prominent clustering of flights and passenger connections at few major airports. The traffic share of the two busiest Brazilian domestic airports (São Paulo/Congonhas Airport (CGH) and Brasília Airport (BSB)) quickly grew and reached their peaks in 2005. In that year, the two airports accounted for one quarter of all travelers and two-thirds of all flight connections in Brazil as the domestic market moved toward a hub-and-spoke design. This movement clearly strained the country's underfunded airport and air traffic control infrastructure (Costa, Lohmann \& Oliveira, 2010).

That strain meant the airport system in Brazil became more vulnerable and prone to flight disruptions. The "big blackout" of air transport in Brazil was a period of massive flight disruptions from October 2006 to July 2007 that was caused by a series of operational slowdowns by air traffic controllers (who were engaging in work-to-rule procedures) and aggravated by the spatial congestion of the air transport system. During this period, flight disruptions (delays and cancellations) more than doubled, affecting 391.4 thousand flights in 2007 compared with 162.3 thousand early in 2004 (National Agency for Civil Aviation, ANAC - see details in Table 1).

This paper's primary focus is on the investigation of the hypothesis of network concentration leading up to the "big blackout". We suspect that network concentration increased in the first years of the decade just before the "big blackout" and that contributed to the emergence and worsening of the major disruptions observed in 20062007. Indeed, with higher network concentration, airlines certainly operate tighter schedules at major airports that can lead to increased risk of flight disruptions, 
particularly under the slowdown in flight management created by air traffic controller's quasi-strike behavior.

We develop an empirical model of network concentration for the air transport industry in Brazil. To our best knowledge, this model is the first to insert network concentration indexes as dependent variables in an econometric model. In so doing, we employ the Network Concentration Gini Index $\left(\boldsymbol{N C}_{\boldsymbol{G I N I}}\right)$ and also develop a Network Concentration Herfindhal-Hirschman Index $\left(\boldsymbol{N} \boldsymbol{C}_{\boldsymbol{H} \boldsymbol{H}}\right)$ for our empirical analysis. We estimate the effects of demand, cost and competition drivers on network concentration and focus on the effects of the "big blackout", in particular. Finally, we make use of sequential quarter dummy variables to estimate the dynamic pattern of the evolution of network concentration before and after the "big blackout", using a regression-based event study. We believe our analysis will improve the understanding of the behavior of air transport systems that are subject to concentration and congestion. This paper also contributes to a growing body of literature that addresses the impact of regulatory policy measures on (de)concentration of airline/airport networks, particularly in emerging economies (Daramola, \& Jaja, 2011; Koo \& Lohmann, 2013; Shaw, Lu, Chen, \& Zhou, 2009).

This paper is structured as follows: In Section 1, we discuss the evolution of the airline network in Brazil and the circumstances surrounding the "big blackout". In Section 2, we discuss the most commonly used metrics of airline network concentration and present our developments of the $\boldsymbol{N C}_{\boldsymbol{G I N I}}$ and $\boldsymbol{N} \boldsymbol{C}_{\boldsymbol{H} \boldsymbol{H I}}$ indexes. Section 3 contains our empirical modeling and the presentation of estimation results. The final section contains concluding remarks. 


\section{Network concentration in Brazilian air transport and the "big blackout"}

\subsection{Liberalization, competition and network concentration}

Liberalization of air transport in Brazil has its origins in the early 1990s with the abolition of the governmental policy known as the "Integrated System of Regional Air Transport" (Sistema Integrado de Transporte Aéreo Regional - SITAR) and its strict structure of five regional monopolies and four national airlines. Abolishing SITAR meant eliminating the controls over the sector's strategic variables, such as price and flight frequency settings and network design; a new airline market began to form in the country that included the entry of small newcomers and low-cost carriers, which led to increased competition. Consistent with international experience with economic liberalization, instituting the freemarket policy generated indisputable gains for the Brazilian airline industry, such as lower prices, increased operational efficiency, and more competitive companies, which led to marked industry expansion. According to the regulator, the average yield dropped by $56 \%$, demand increased by $234 \%$ and the average load factor increased by $21.5 \%$ following deregulation (source: National Agency for Civil Aviation's Air Transport Yearbook, 2012).

However, such liberalization was not accompanied by investment in the infrastructure components that constitute the air transport supply chain, such as airports and the air traffic control sector. Furthermore, all the country's major airports continued to be operated by the state-owned company INFRAERO until 2012, when a process of airport privatization was initiated. São Paulo/Guarulhos International (GRU), São Paulo/Campinas (VCP) and Brasília (BSB) airports were privatized in 2012. Subsequently, in 2013, operations at Rio de Janeiro/Galeão (GIG) and Belo Horizonte/Confins (CFN) were also transferred to the private sector. Air traffic control remained under the supervision of the Department of Airspace Control (Departamento de Controle do Espaço 
Aéreo - DECEA), which is a government body under the Ministry of Defense. Due to factors such as lack of both flexibility and innovation in airport management and public underinvestment over the years - as reported in 2006 by the Brazilian Federal Court of Accounts (whose acronym in Portuguese is TCU), a fiscal watchdog of the federal government - there was a clear mismatch between the fast-growing domestic airline market and slow-motion change in airport infrastructure (Tribunal de Contas da União (2006) AC-2420-50/06-P. "Relatório de levantamento de auditoria [Audit Report]", available at www.contas.tcu.gov.br.). On the problems of infrastructure underinvestment in Brazil, a Morgan Stanley report stated, "Infrastructure spending in Brazil has been in a declining trend over the past 40 years, averaging 5.4\% of GDP during the 1970 s, $3.6 \%$ in the 1980 s, $2.3 \%$ in the 1990 s, and $2.1 \%$ in the 2000s." (Morgan Stanley Blue Paper, May 5, 2010, p. 3).

In parallel with these developments, other factors associated with a more liberalized environment began to emerge, such as a strong decline in the number of destinations served by carriers across the country and an increased concentration of flight frequencies at major nodes of the airline network structure (Koo \& Lohmann, 2013). Indeed, after deregulation, the dynamics of a more competitive market led established carriers to increasingly pursue cost efficiency, and the quickest way of accomplishing this goal was to target the creation of economies of traffic density and scope, with a particular focus on the densest routes of the country. Therefore, since the early 2000s, the network design of Brazilian airlines evolved rapidly toward higher concentrations of flights and passenger connections in a small number of major airports. Figure 1 presents the evolution of the traffic share of the two busiest Brazilian domestic airports, CGH in São Paulo and BSB in Brasília. Investigating the long-run progression of these airports reveals a fundamental feature of the evolution of airline networks in the country as these two airports witnessed a sizeable increase in their shares of domestic flights, domestic passengers and domestic connecting passengers beginning in the early 1990s and continuing until immediately 
before the "big blackout" (2003-2005). Figure 1 shows that, during the 2003-2005 period, these two airports together accounted for $21 \%$ of all domestic flights (up from $15 \%$ in 1991-1993), 32\% of all domestic passengers (up from 16\% in 1991-1993) and a notable $63 \%$ of all domestic connecting passengers (up from $10 \%$ in 1991-1993).

Possible explanations for the network concentration movement toward São Paulo Congonhas and Brasília airports, as observed in Figure 1, may be associated with two factors: (a) natural competitive advantage and (b) entry barriers. First, it is clear that geographic location and economic factors make the two airports attractive and strategic places for the operations of any major airline in the country. São Paulo, which has the largest GDP and population in Brazil, and Brasília is central to the country's territory, in addition to being the political capital that generates a significant amount of traffic from/to all states of the country. Second, following the airline economic deregulation of the late 1990s, all carriers enjoyed the freedom not only to set prices according to market conditions but also to adjust their network design with flight expansions and reallocations across the country. The major competing airlines, i.e. Varig, TAM and Gol, used São Paulo Congonhas and Brasília as important parts of their strategic business plans to grow, block the entry of newcomers and so reap increased profits. Entry barriers (via slot controls at these airports) were clearly established during that period. As an illustration of this approach, Gol acquired Varig in 2007 mainly to obtain airport slots and strengthen its position at São Paulo Congonhas. The result of these strategic decisions since deregulation was that the two busiest airports were highly congested (Costa, Lohmann \& Oliveira, 2010), which caused a severe strain on the country's underfunded airport infrastructure.

\subsection{The "big blackout" period}

The "big blackout" of air transport in Brazil, also known as the "Apagão Aéreo" or simply "Air Blackout" - an allusion to the energy blackout of the country in 2001 - was a period of massive flight disruptions that lasted from October 2006 until July 2007. Structurally, the 
"big blackout" was a clear result of the pressure from the rapid growth in airline demand on an underfunded airport and air traffic control infrastructure and was expressed in a wave of flight delays and cancellations. The situation in the "big blackout" period was exacerbated by an operational slowdown by air traffic controllers - a quasi-strike implemented mainly with work-to-rule actions (i.e. workers following very strict and minor rules in order to intentionally slow the ordinary flow of work) - after the crash of Gol Flight 1907 in September 2006. Most of the disruptions produced by the "big blackout" came to an end soon after a second tragic event - the crash of TAM Flight 3054 at São Paulo Congonhas, on July 17, 2007. After this second crash, aviation authorities imposed operating restrictions on this airport, such as a perimeter rule and a ban on flight connection operations by carriers (Lohmann \& Trischler, 2012). Simultaneously, the air traffic controllers work action ultimately ceased, and airline, airport and air traffic control operations returned to normal across the nation.

\subsection{Evolution of flight delays in the 2000s}

Table 1 presents the evolution of flight disruptions in Brazil from 2004 to 2010 and shows that flight disruptions more than doubled during the "big blackout" period - reaching 391.4 thousand flights in 2007 from 162.3 thousand early in 2004. In the worst year delays and cancellations affected 137.8 and 253.6 thousand flights, respectively, and nearly $60 \%$ of domestic flights were disrupted.

\section{[insert Table 1 about here]}

Later in the decade, flight disruptions began to decline, and by 2010 , they reach lower levels than experienced before the "big blackout", at $24.4 \%$ of all flights. Currently, after the privatization of major airports of the country, flight disruptions are no longer reported as a major problem by air transport authorities. For example, during the 2014 FIFA World 
Cup, when the Brazilian airport system was used by more than 16 million passengers and approximately one million international tourists over a period lasting less than two months, traffic delays affected approximately $7 \%$ of flights (Source: National Secretary for Civil Aviation www.aviacaocivil.gov.br and Ministry of Tourism www.turismo.gov.br and www.copa2014.gov.br). This declining trend of flight disruptions makes the "big blackout" episode more intriguing and relevant for investigating the concentration and major disruption of air transport systems subject to rapid market growth and service reorganisations.

\section{Assessing airline network concentration}

\subsection{Measures of airline network concentration}

Economic measures of concentration are widely employed to indicate how a particular market is structured. The airline market is no exception, and these measures may be used provided they have certain desirable features (Reynolds-Feighan, 1998 and 2001; Hall, 1967), including one-dimensionality and independence from the size of the studied market.

The primary advantage of concentrated hub-spoke (HS) networks is that they enable airlines to lower travel costs and increase connectivity (Pels, 2001). Airlines can decrease travel costs by gathering a group of passengers with the same origin and different destinations on flights that feed the hub. These passengers are redistributed onto different connecting flights, leaving the hub for their final destinations. Connectivity is increased within a hub because there is a concentration of landings and take-offs during certain time periods, which are commonly referred to as hub waves (Alderighi, 2005). A hub airport can increase airline productivity, but it can also have detrimental effects on the overall air transport industry. The first negative aspect is that a hub grants a degree of monopoly power over airport facilities to airlines operating hubs (Nero, 1999). In addition, 
operational overload at times during the day is common at hubs, which increases delays and passenger dissatisfaction, creates barriers to new entry at the airport, and increases air traffic congestion, which can overload air traffic controllers and compromise safety (Button, 2002, Hoffman, 2000, Rodrigue, 2006).

\section{The Network Concentration Gini Index $\left(N C_{G I N I}\right)$}

An index for measuring air transport concentration frequently found in the literature is the Gini index (Burghouwt, Hakfoort \& van Eck, 2003, Huber, 2009, Koo and Lohmann, 2013, Reynolds-Feighan, 2001). This index first appeared in the research of Corrado Gini, the statistician who sought to express a distribution's difference from uniformity (Gini, 1913). Widely used to measure wealth and income inequality, it was only introduced into the analysis of air transport by Reynolds-Feighan (1998), who used it to measure spatial concentration in U.S. airline networks. The Gini index can be defined as:

$$
\text { Gini }=\left|1-\frac{1}{N} \sum_{i=1}^{n}\left(\sigma Y_{i}+\sigma Y_{i-1}\right)\right|,
$$

where $n$ is the number of airports in the network and $\sigma Y_{i}$ is the cumulative traffic from the busiest airport to the $i$-th busiest airport. One advantage of the Gini index is that it is not sensitive to population distribution and responds well to changes in any segment of the population, whether the changes occur in small, medium or large airports (Huber, 2009). Calculating the Gini index does not require a homogeneous or well-defined market. However, according to Burghouwt, Hakfoort \& van Eck (2003), the Gini index exhibits two flaws that contradict the characteristics cited by Hall (1967): it does not range from zero to one and depends on the size of the studied market. To eliminate these problems, these authors introduced a new index, the Network Concentration Index (here labeled as 
$\boldsymbol{N} \boldsymbol{C}_{\boldsymbol{G I N I}}$, which is calculated as the Gini index divided by the maximum Gini possible for that network:

$$
N \boldsymbol{C}_{\text {GINI }}=\frac{\text { Gini }}{G_{\max }}
$$

where $G_{\max }$ is the maximum Gini index in a network, given by $G_{\max }=1-2 / n$, with $n$ being the number of airports in the network.

\section{The Network Concentration HHI Index $\left(\mathrm{NC}_{\mathrm{HHI}}\right)$}

The other index commonly used to measure air transport concentration is the HerfindahlHirschman Index (HHI) (Huber, 2009, Martín \& Voltes-Dorta, 2009, Papatheodorou, 2009, Reynolds-Feighan, 2001, Lijesen, 2004). Orris Herfindahl and Albert Hirschman developed the index in 1950 (Hirschman, 1964) to measure the concentration of companies in a particular industry. This index is widely used in antitrust cases for assessing the competitive effects of a proposed merger. In air transport, it has been used as a substitute for or competitor of the Gini index when assessing network concentration. The HHI is given by:

$$
H H I=\sum_{i=1}^{N} s_{i}^{2},
$$

where $s_{i}$ is the participation in the traffic of airport $i$. The primary limitation of the HHI is that it depends on the size of the analyzed market. It is also regarded as a poor measure because it can be derived from the parameters of the underlying size distribution (Reynolds-Feighan, 2001). 
One advantage of this index is that it is only sensitive to changes in the extremes of the studied population, which is ideal when studying hubs, for example. Applying this line of reasoning, Costa, Lohmann \& Oliveira (2010 and 2011) used the HHI to develop a model to measure the number of theoretical hubs in a given network. In this paper, we build upon that framework to develop a network concentration version of the $\mathrm{HHI}$ in a similar fashion as Burghouwt, Hakfoort \& van Eck (2003), considering two airport categories: hub airports and spoke airports. By definition, a hub is an airport through which all originating traffic is channeled. For our purposes, we have set a constraint that, in a pure hub-andspoke system, $50 \%$ of all landings and takeoffs are concentrated in hubs, whereas the remaining $50 \%$ of landings and take-offs are distributed among the spokes. Therefore, by applying the HHI to the network of $h$ hubs and $(n-h)$ spokes, the following is obtained:

$$
H H I(n, h)=\sum_{i=1}^{h} s_{h i}^{2}+\sum_{j=1}^{n-h} s_{s j}^{2}
$$

where $n$ is the number of airports in the network, $h$ is the number of hub airports in the network, $s_{h i}$ is the traffic participation of a hub airport and $s_{s i}$ is the traffic participation of a spoke airport. By imposing symmetry and using the definition of hub, the following is obtained:

$$
\begin{gathered}
H H I=H H I(n, h)=\left(\frac{0.5}{n}\right)^{2} h+\left(\frac{0.5}{n-h}\right)^{2}(n-h) \\
H H I(n, h)=\frac{0.25 n}{h(n-h)}
\end{gathered}
$$

Given the maximum concentration, there would be only one hub with $50 \%$ of the traffic, and in this situation, we have: 


$$
H H I_{\text {max }}=H H I(1, h)=\frac{0.25 n}{(n-1)}
$$

With Equation (6), it is possible to reach a network concentration index similar to that proposed by Burghouwt, Hakfoort \& van Eck (2003) - here labeled as $\boldsymbol{N C}_{\boldsymbol{G I N I}}$. We suggest the following implementation, combining Equations (5) and (6) to produce a Network Concentration $\mathrm{HHI}, \boldsymbol{N} \boldsymbol{C}_{\boldsymbol{H H I}}$ :

$$
N C_{H H I}=\frac{H H I}{H H I_{\max }},
$$

where $H H I_{\text {max }}$ is the maximum HHI index in a network, given by $H H I_{\text {max }}=0.25 n /(n-$ 1), with $n$ being the number of airports in the network. The $\boldsymbol{N C}_{\boldsymbol{H} \boldsymbol{H} \boldsymbol{I}}$ has the desirable property of ranging between 0 and 1 , with the theoretical maximum 1 representing a full hub-and-spoke system.

\subsection{Analysis of the evolution of network concentration using $N C_{G I N I}$ and $N C_{H H I}$}

Using Brazilian airport data, we present an analysis of the evolution of network concentration in the country by employing the above described network concentration indexes, namely the $\boldsymbol{N C}_{\boldsymbol{G I N I}}$ and the $\boldsymbol{N} \boldsymbol{C}_{\boldsymbol{H} \boldsymbol{H I}}$. The dataset used to compare the indexes derives from the INFRAERO monthly air passenger statistic report, which is available at the operator's website. This database contains the records of all passengers who passed through the 61 largest airports operated by INFRAERO during the 2002-2008 period. In comparison, network concentration was relatively high in the early 2000s (average $N C_{G I N I}$ and $\boldsymbol{N} C_{H H I}$ of 0.801 and 0.591 , respectively, in 2000) and relatively low in the late 2000s (average $\boldsymbol{N} \boldsymbol{C}_{\boldsymbol{G I N I}}$ and $\boldsymbol{N} \boldsymbol{C}_{\boldsymbol{H} \boldsymbol{H I}}$ of 0.794 and 0.435 , respectively, in 2010). For this reason and to better illustrate the potential effects of the "blackout" event (the focus of 
attention here), we restrict our attention Figure 2 presents the monthly values of each network concentration index.

[insert Figure 2 about here]

Analyzing the two indexes calculated over this period, we note a visual correlation. Indeed, both indexes display a similar time pattern, with an increase from 2002 to 2004, reaching a peak in 2005 (a year before the "big blackout"), and systematically declining toward the end of the decade. The evolution analysis shown in Figure 2 is thus consistent with our comments on the role of these two airports in Section 1. The Pearson correlation coefficient between the two monthly coefficients was high at 0.762 , which means that both indexes may be reasonably used as proxies for assessing changes in network concentration quite interchangeably. However, there is a difference between them that justifies looking at both separately. This difference is in the sample distribution of each index. In our sample the $\boldsymbol{N C}_{\boldsymbol{G I N I}}$ always presented a larger mean and a lower standard deviation than the $\boldsymbol{N C}_{\boldsymbol{H} \boldsymbol{H} \boldsymbol{I}}$ : the computed monthly mean of $\boldsymbol{N} \boldsymbol{C}_{\boldsymbol{G I N I}}$ was 0.800 with a standard deviation of 0.007 , whereas the monthly mean of $\boldsymbol{N C}_{\boldsymbol{H} \boldsymbol{H} \boldsymbol{I}}$ was 0.527 with a standard deviation of 0.053 . This fact indicates that the higher sample variability of the $\boldsymbol{N} \boldsymbol{C}_{\boldsymbol{H} \boldsymbol{H} \boldsymbol{I}}$ might allow this index to present higher goodness-of-fit statistics when employed as a dependent variable in a regression analysis. Notwithstanding this characteristic, we decided not to discard the results for the Gini index, however, because we believe they constitute a way of confronting the results for the HHI and therefore to provide an important check of robustness of our analysis.

\section{Empirical model of network concentration determinants}

The chief objective of this section is to investigate the determinants of airline network concentration in Brazil in the 2000s with an econometric model of the concentration indexes $\boldsymbol{N C}_{\boldsymbol{G I N I}}$ and $\boldsymbol{N} \boldsymbol{C}_{\boldsymbol{H} \boldsymbol{H} \boldsymbol{I}}$. From our previous description of the period, we suspect that 
concentration may have increased in the first years of the decade just before the "big blackout" and may thus have contributed to the emergence and worsening of the major disruptions observed in 2006-2007. Moreover, the de-concentration movement of the post-blackout period may have played a role in producing the decline observed in the number of flight disruptions since 2008. Some of the reasons for the move toward deconcentration in the late 2000s included the fact that: (1) São Paulo airports had reached full capacity and experienced rapid growth in air transport demand in parallel with other regions of the country; and (2) the enhanced competition stemming from the LCC Azul Airlines based at the secondary São Paulo/Campinas Airport.

Our focus here is on the evolution of network concentration and the potential vulnerability to delays and cancellations of the air transport system leading up to and during the "big blackout" period. We therefore perform a formal hypothesis test of the relation between concentration and the "big blackout" period. In the following, we will present our metrics of network concentration and later use them as regressands in an econometric model to determine whether the "big blackout" period (before, during and after the event) was marked by a higher concentration of airline networks.

\subsection{Data}

The data used in our empirical framework were provided by INFRAERO. These data represent $83.8 \%$ of all airline passengers in Brazil (Source: dataset, ANAC's 2008 statistical yearbook and own calculations). The dataset's structure comprises monthly statistics over the January 2000-December 2010 period for all domestic and international enplanements and deplanements at 59 airports operated by the company. The total sample size is 132 observations (11 years times 12 months). Domestic traffic comprised $89.7 \%$ of total traffic in the 2010 data. All local and connecting passengers on scheduled flights are accounted for in our analysis. Regions with multiple airports - São Paulo, Rio de Janeiro and Belo Horizonte - are grouped to form a multiple airport region (MAR). The 
decision to group all airports in multiple airport regions is clearly debatable in light of our analysis and warrants further discussion. Indeed, the use of a multiple-airport regions (MAR) approach for congestion analysis is much more sensible when airports are close enough together to share local scale air traffic control space. We justify this methodological step by confirming that the airports that were grouped belong to either the same city (Rio de Janeiro's airports) or the same metropolitan region (Belo Horizonte and São Paulo's airports). None of the included airports can be considered a distant secondary airport. On the contrary, all groups consisted of primary airports belonging to the same region located within each other's catchment area circles with rays under 25 miles. Finally, all groups included airports that belong to the same official designated area of controlled airspace of the city - the "Terminal Maneuvering Area" (TMA) - according to the regulations of the Department of Airspace Control. In this sense, we believe that these airports may be regarded as close enough to conceive of congestion at the city level. A given MAR's share of traffic is equal to its traffic divided by INFRAERO's total traffic. This share is ultimately used to calculate the network concentration indexes that constitute the regressands of our empirical models.

\subsection{Empirical model}

We perform a regression-based event methodology ${ }^{1}$ to inspect the evolution of the levels of network concentration before, during and after the "big blackout". Binder (1998) reports that the event study methodology is commonly used for measuring the price reaction of securities to announcements or events in financial markets by investigating changes in security prices within a time window. To our best knowledge, Whinston and Collins (1992) and Goolsbee and Syverson (2008) were the first to employ the regression- 
based event methodology to examine airline markets - in the latter case, with a nonfinancial application that examined incumbent airline prices around events of low-cost carrier actual and potential entry. By looking at the periods within a window of months before, during, and after the event, while controlling for other influences such as demand and competition, we are able to formally test whether, ceteris paribus, the "big blackout" is correlated with exaggerated network concentration. Our time window comprises the period from eight quarters before the first flight crash (Gol Flight 1907 on September 29, 2006) up to eight quarters following the second flight crash (TAM Flight 3054 on July 17, 2007). As discussed above, the period between the crashes is widely acknowledged in Brazil as being the period of major flight disruptions caused by the air traffic controllers' slowdown work actions. Our empirical model is therefore the following:

$$
\begin{aligned}
\lg \left(N C_{t}\right) \equiv \ln \left(\frac{N C_{t}}{1-N C_{t}}\right) & =\beta_{0}+\beta_{1} \text { domestic pax }_{t}+\beta_{2} \text { international pax }_{t} \\
& +\sum_{\tau=-8}^{+8} \delta_{\tau} \text { blackout }_{t^{*}+\tau} \\
& +\gamma_{0} \text { trend }+\gamma_{m} \text { dummy month } m+\varepsilon_{t},
\end{aligned}
$$

where $N C_{t}$ is the Network Concentration Index - either $\boldsymbol{N C}_{\boldsymbol{G I N I}}$ or $\boldsymbol{N} \boldsymbol{C}_{\boldsymbol{H} \boldsymbol{H I}}$ - over time; $\ln \left(N C_{t}\right)$ is the logit transformation of $N C_{t}$, which is the traditional procedure to fit a model when the dependent variable is bounded by 0 and 1 ; domestic pax dond and international pax $_{t}$ are the number of domestic and international enplanements plus deplanements at INFRAERO's airports, respectively; jet fuel price ${ }_{t}$ is a proxy for the average jet fuel price (source: ANAC), calculated by dividing total jet fuel costs by the total fuel consumption of all domestic airlines; effective competitors $s_{t}$ is the the number of average effective airline rivals on the domestic routes, which is equal to the inverse of the HHI that is based on the market shares of each airline on each route. 
Although the focus of the paper is on the domestic market, we are aware that international traffic density creates special conditions for hub development. This is particularly true for the major gateways of the country, such as São Paulo/Guarulhos (GRU) and Rio de Janeiro/Galeão (GIG). With enough international traffic, carriers have enough economies of scope and density to fortify their operations in the associated airports. In other words, network concentration in international travel markets is usually highly correlated with network concentration in domestic markets, being therefore a good proxy for unobserved airline incentives to fortify network positions at major airports. This is the main justification for having international pax $t$ in our list of regressors.

Historic jet fuel unit cost series and all other variables measured in units of money, e.g. the gross domestic product (GDP) used as an instrumental variable, were originally expressed in nominal local currency (BRL). They were converted into real monetary figures with inflation adjustment using the Consumer Price Index IPCA from the Brazilian Institute of Geography and Statistics (IBGE). Real jet fuel unit cost was then transformed from real BRL per liters into US dollars per gallons by using the average 2010 BRL/USD exchange rate. The idea of this procedure is to permit straightforward comparisons with international airlines.

Our event analysis of the association of the "big blackout" and network concentration in Brazil is developed via the sequential blackout $_{t^{*}+\tau}$ dummies $(\tau=-8,-7, \ldots, 0, \ldots, 7,8)$, where $t^{*}$ is the beginning of the event window, i.e. the month subsequent to the first air crash, October 2006. In other words, the seventeen blackout binary variables are quarter dummies surrounding the period when the air traffic controllers triggered slowdown procedures and the "big blackout" was in effect. All dummies are mutually exclusive such that the implied effects on the dependent variable given by their coefficients are not additive. To check the robustness of our results, we also experimented with less "deep" specifications of the time dummies. We therefore employed two alternative specifications: 
(a) the first with only a single dummy variable named "blackout-during", which was set to one only for the months between the two aircraft crashes, i.e. for all months pertaining to $\tau=\{0,1,2\}$; and (b) the second with three dummies: the "blackout-before" dummy (where $\tau=\{-8,-7, \ldots,-1\}$ ), the "blackout-during" dummy (where $\tau=\{0,1,2\}$ ), and the "blackout-after" dummy (where $\tau=\{3,4, \ldots, 8\}$ ).

We also include controls for seasonality (dummy month $\mathrm{m}$ ) and economic trend (trend). Airline demand is known to be highly seasonal; in Brazil, the summer (December to February) and the mid-year vacation season (July) are the strongest periods. Additionally, demand for the air travel in Brazil has grown rapidly within the sample, fueled not only by economic growth but also by the growing numbers of middle-class consumers. Because of these factors, we include seasonality and trend controls. Finally, $\varepsilon_{t}$ is the error term. Table 2 presents descriptive statistics of the most important variables used in the econometric study.

[insert Table 2 about here]

\subsection{Empirical strategy}

In our estimating framework, we posit that demand (either domestic or international) and competition (effective competitors) are potentially correlated with unobserved components of network concentration, i.e. with the unobserved error term $\varepsilon_{t}$ in Equation (8). For example, time-varying factors of income distribution and industrial geographic dispersion across the country are potential unobserved determinants of network concentration that may be correlated with any of these variables. Because our main concern is to correctly estimate coefficients associated with demand and competition to obtain a consistent partial effect estimate of the blackout dummies, we must thus employ an instrumental variables estimator (for comparison purposes, we present the results of 
the OLS estimation in the Appendix). Our identification strategy used key exogenous demand shifters as instrumental variables. In particular, as instruments we used gross domestic product (GDP), current and lagged one period, and the proportion of credit operations relative to GDP (total credit in the economy and total industrial credit, all lagged one period). The structural motivation for these instruments relies on the fact that they are key demand drivers. It is acknowledged that the expansion of credit availability during the 2000s played a major role in allowing not only consumers to increase their demand for durable goods and air travel but also companies to expand their size and operations. In the case of the $\boldsymbol{N C}_{\boldsymbol{G I N I}}$ index, due to its lower sample variability, we also had to use the share of international passengers (relative to total passengers in Brazil and lagged one period) as an additional instrument.

We employed tests of the validity and relevance of the proposed instrumental variables to analyze the quality of the identification strategy described above. First, the validity of the full set of over-identifying conditions was challenged by Hansen J tests. This test checks whether the model is overidentified, i.e. whether the number of instruments excluded from the equation is statistically larger than the number of included endogenous variables. Rejection of the null hypothesis implies that instruments do not satisfy the orthogonality conditions, and one obvious reason is that they are not truly exogenous. For both $\boldsymbol{N C}_{\boldsymbol{G I N I}}$ and $\boldsymbol{N} \boldsymbol{C}_{\boldsymbol{H} \boldsymbol{H I}}$ cases, the Hansen J tests did not reject orthogonality. Note that the Hansen J test has a non-conservative null hypothesis because it assumes orthogonal instruments. It is non-conservative because is it well known in the literature that good instruments are typically hard to find. To increase the power of the test and thus avoiding Type II error acceptance of a false null - we adopted a significance level of $25 \%$. Even with stricter significance levels - in this case, a broader critical region - we could not reject the null hypothesis in any situation. 
Second, the relevance of the proposed set of instruments was challenged by means of underidentification tests. The underidentification test is a LM test of whether the equation is identified, i.e. that the excluded instruments are "relevant" or correlated with the endogenous regressor uses. The test employs the Kleibergen-Paap rk LM statistic (KP). The KP statistics for $\boldsymbol{N C}_{\boldsymbol{G I N I}}$ and $\boldsymbol{N} \boldsymbol{C}_{\boldsymbol{H} \boldsymbol{H I}}$ allowed us to reject the null of underidentification at the $10 \%$ level.

The estimation method employed is the equation-by-equation two-step feasible efficient generalized method of moments (2SGMM) estimator with statistics robust to arbitrary heteroskedasticity and autocorrelation. Given the monthly periodicity of the dataset, the bandwidth used in the estimation with a Newey-West (Bartlett) kernel was set equal to 12. Angrist \& Pischke (2008) suggest the use of LIML as a crosscheck of over-identified estimates. They specifically refer to crosschecking 2SLS with LIML results, arguing that LIML is less precise but also less biased than 2SLS. Because we use 2SGMM, we crosschecked the robustness of our results with the two alternative estimators. The results are available in the Appendix (2SLS and LIML) and were very similar.

\subsection{Estimation results}

Table 3 presents the estimation results for the empirical model of network concentration in Brazil. All estimated values represent the elasticity of the dependent variable associated with the respective regressor and extracted at the sample mean of regressand and regressor. As it is not a log-log specification, estimated elasticities are not equal to the estimated coefficients. We prefer reporting elasticities rather than coefficients because they are invariant to the scale of variables and have straightforward interpretations. As Table 3 shows, we experimented with different specifications for the regressions of each concentration index employed, i.e. $\boldsymbol{N} \boldsymbol{C}_{\boldsymbol{H H I}}$ (Columns 1-3) and $\boldsymbol{N} \boldsymbol{C}_{\boldsymbol{G I N I}}$ (Columns 4-6). The difference between columns within the same regressand is related to how "deep" we 
specified the dummies controlling for the blackout period, as discussed above. Hence, in Columns (1) and (4) we have only the "blackout-during" dummy, in Columns (2) and (5) we have the "blackout-before", "blackout-during" and the "blackout-after" dummies and, finally, in Columns (3) and (6) we have the sequential quarter dummies "blackout $t^{*}+\tau^{\text {", }}$ $\{\tau=-8, \ldots, 0, \ldots,+8\}$.

Note that the Adjusted R-Squared of the $\boldsymbol{N C}_{\boldsymbol{H} \boldsymbol{H I}}$ specifications are systematically higher than the equivalent $\boldsymbol{N C}_{\boldsymbol{G I N I}}$ specifications. For example, the Adjusted R-Squared in Column (1) is 0.5087, compared with 0.9406 in Column (4). This fact is more indicative of the notably lower variability of the $\boldsymbol{N C}_{\boldsymbol{G I N I}}$ series than the actual lower quality of adjustment of its regressions relative to the $\boldsymbol{N C}_{\boldsymbol{H} \boldsymbol{H I}}$. In addition, it is notable that the RMSE of all $\boldsymbol{N} \boldsymbol{C}_{\boldsymbol{G I N I}}$ specifications are lower.

A core result of our estimations is that higher traffic volumes in the domestic market tend to decrease network concentration whereas higher international traffic flows go in the opposite direction, i.e. to increase such concentration. Another possible ex-ante expectation would be a positive association between domestic traffic and network concentration. Although a potentially reasonable relation, a positive association was not confirmed by our main results. This may be indicative of capacity constraints being more binding to the domestic than to international operations and thus revealing the preferences of airport management authorities in the two major international gateways. Additionally, it may reveal that carriers perceive that a higher potentiality for traffic growth is not present in the major metropolitan areas but is latent in medium-sized cities across the country.

This result is robust to variations in all specifications of Table 3 - and also specifically in our preferred specifications in Columns (3) and (6). Indeed, the variables "domestic pax" and "international pax" have coefficients with negative and positive signs, respectively, and are both statistically significant across most columns. We interpret these findings as 
an indication that international air traffic in Brazil tends to be channeled through a few major gateway airports - particularly through São Paulo-Guarulhos International Airport (GRU). We distinguish between domestic and international passenger traffic because (based on the network design of carriers aiming at economies of scope) the availability of international flights typically constitutes a considerable source of domestic traffic - and of network concentration as a result - due to the competitive advantages of the international gateway airports in contrast to exclusively domestic airports. However, domestic traffic increases appear to be pushed by the attraction of demand at medium-sized airports rather than major hubs such that concentration tends to decrease as domestic demand grows.

[insert Table 3 about here]

With respect to the explanatory variables of costs and competition ("jetfuel price" and "effective competitors"), the results were not statistically significant in general. We believe that multicolinearity may have inflated the standard errors of these coefficients as indicated by the VIF statistics discussed above. We experimented with dropping the regressor domestic pax and the results of both variables became statistically significant in almost all specifications, which indicates that these variables may have an important influence on network concentration but only via the domestic demand variable (results presented in the Appendix). Dropping domestic passenger did not cause our RESET statistics to be damaged but we believe this model is misspecified. Additionally, in this experiment, the KP statistics were affected, showing that some instruments were relevant only to identify the domestic pax variable. Disregarding the statistical significance and focusing only on estimated signs, our results suggest that fuel cost hikes (jetfuel price) tend to increase concentration and that enhancements in competition (effective competitors) tend to decrease it. We therefore conclude that there is only rudimentary evidence on the relation between those variables and that further investigation is needed. 
With respect to our main focus, the "big blackout" dummies, we have a clear indication that overall the network of airlines in the sample period was more concentrated both before and during the blackout event than in the remainder of the dataset. Because network concentration was pointed to as a possible cause for the vulnerability of the air transport system in Brazil during the "big blackout", we therefore consider these findings as the most important of our analysis. First, Columns (1) and (4) show that the "blackoutduring" dummy had a positive sign and was statistically significant in both cases $(0.0324$ and 0.1088 , respectively). When decomposing the effect of that dummy into three different periods ("blackout-before", "blackout-during" and "blackout-after", in Columns 2 and 5), the pre-blackout period is certainly the most robust across specifications. When breaking down the effects into subsequent quarter dummies - Columns 3 and 6, our preferred specifications - we can see the pattern of evolution of network concentration more clearly. Indeed, there is evidence that network concentration increased at least six quarters previous to the actual blackout period and stayed high until at least two quarters after the beginning of the blackout. This pattern is clearer for $\boldsymbol{N} \boldsymbol{C}_{\boldsymbol{H} \boldsymbol{H} \boldsymbol{I}}$ but is also observed for the $\boldsymbol{N C}_{\boldsymbol{G I N I}}$ in almost all quarters. Delving deeper, we conducted Wald tests of the joint nullity of all quarter dummies either before $t^{*}$ or after $t^{*}$ for both concentration indexes. All hypothesis tests soundly rejected the null of joint nullity of coefficients and therefore provided evidence to support the suggested pattern of evolution (the calculated Fstatistics for the tests of joint nullity of the seventeen dummy variables in Columns (3) and (6) were 450.24 and 379.99, respectively. Both tests soundly rejected the null hypothesis). Notably, the results of Columns (3) and (6) have the highest R-squared and the lowest RMSE among the different alternatives.

These results may indicate that higher network concentration preceded the blackout period and may have contributed to cause and aggravate the problem. Although the slowdown of air controllers was the salient trigger for the "big blackout" in Brazil, we may have evidence that network concentration also played an important role in aggravating 
flight disruptions. Alternatively, we may at least conclude that it was a period when the network was more dependent on - and thus more vulnerable to - the operating conditions of the major airports in Brazil.

Note that from quarter $t^{*}+3$ to quarter $t^{*}+5$, both models suggest that there was a decrease in network concentration. This result may be interpreted as a reaction of carriers attempting to reorganize their networks and engaging in crisis management while aiming to relieve the tight schedule operations of that time. They might have accomplished such a "dehubbing" pattern by cutting some flight frequencies at major airports.

Figure 3 illustrates the estimated pattern of the evolution of network concentration by presenting the evolution of the estimated coefficients of the blackout quarter dummies from Columns (3) and (6). In other words, we present the evolution of the estimated percent changes of both indexes during the time window under consideration. Note the significant drop from $t^{*}+3$ in both series.

[insert Figure 3 about here]

The post-blackout period results also merit some discussion. After the fifth quarter from the beginning of the blackout period, the alternative models apparently diverge with respect to the long-run consequences for network concentration in Brazil. Whereas the

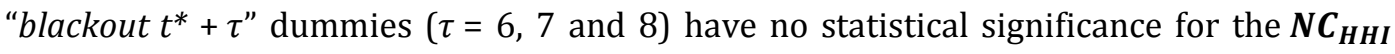
specification (Column 3), they are clearly significant and negative for the $\boldsymbol{N C}_{\boldsymbol{G I N I}}$ specification (Column 6). However, only the $\boldsymbol{N} \boldsymbol{C}_{\boldsymbol{H} \boldsymbol{H} I}$ presented trend effects that were statistically significant. We therefore cannot infer much from these results and again suggest further investigation of the subject.

With respect to the seasonality dummy variables, Table 3 shows that, conditional on the actual domestic and international traffic movements, airline network concentration tends to be higher during periods of higher concentrations of business travelers in total demand. 
Indeed, the periods March-June and August-November are typically associated with more intense business-related air travel in Brazil. Concentration in this case may be a natural consequence of carriers' strategies that re-allocate flights from tourist destinations to routes connecting major cities, thus fortifying their positions and enhancing vertical product differentiation related to schedules to attract time-sensitive business travelers.

\section{Conclusion}

This paper aimed to empirically investigate the determinants of airline network concentration as applied to an air transport system subject to congestion and massive flight disruptions, i.e. the "big blackout" of Brazil in 2006-2007. We performed a regression-based event study with sequential quarter dummy variables to estimate the dynamic patterns of concentration before and after the "big blackout". We employed the Network Concentration Gini Index $\left(\boldsymbol{N} \boldsymbol{C}_{\boldsymbol{G I N I}}\right)$ and also suggested a novel - and easy to construct - Network Concentration Herfindhal-Hirschman Index $\left(\boldsymbol{N} \boldsymbol{C}_{\boldsymbol{H} \boldsymbol{H} I}\right)$ as regressands in our econometric model.

Our main finding was that the airline network was more concentrated both before and during the "big blackout" event than in the remaining sample period, which suggests that concentration may be one reason for the vulnerability of the Brazilian air transport system during the period. In fact, we find that concentration was higher from at least six quarters before the blackout until two quarters after it and was followed by a quick decline toward the end of the decade. This latter result may be interpreted as a reaction of carriers attempting to reorganize their networks from a crisis management perspective and aiming at providing relief in contemporaneous tight-scheduled operations. The carriers actually accomplished such management by cutting some flight frequencies at major airports. 
Acknowledgments

The authors acknowledge the contributions of Prof Kevin O'Connor, Associate Editor Asia Pacific and Africa, as well as of the two anonymous referees that significantly enhanced the overall quality of this paper. The usual disclaim applies.

\section{References}

Alderighi, M., Cento, A., Nijkamp, P., \& Rietveld, P. (2005) Network competition - the coexistence of hub-and-spoke and point-to-point systems. Journal of Air Transport Management, 11, 328-334.

Angrist, J. D., \& Pischke, J. S. (2008) Mostly harmless econometrics: An empiricist's companion. Princeton: Princeton University Press.

Binder, J. J. (1998) The event study methodology since 1969. Review of Quantitative Finance and Accounting, 11, 111-137.

Burghouwt, G. (ed.) (2007) Airline network development in Europe and its implications for airport planning, Hampshire: Ashgate.

Burghouwt, G., Hakfoort, J., \& Van Eck, J. R. (2003) The spatial configuration of airline networks in Europe. Journal of Air Transport Management, 9, 309-323.

Button, K. (2002) Debunking some common myths about airport hubs. Journal of Air Transport Management, 8, 177-188.

Costa, T. F. G., Lohmann, G., \& Oliveira, A. V. M. (2010) A model to identify airport hubs and their importance to tourism in Brazil. Research in Transportation Economics, 26, 311.

Costa, T. F. G., Lohmann, G., \& Oliveira, A. V. M. (2011) Assessing Concentration and Identifying Hubs in the Brazilian Air Transportation Industry. Journal of Transport Literature, 5, 106-133. 
Daramola, A., \& Jaja, C. (2011). Liberalization and changing spatial configurations in Nigeria's domestic air transport network. Journal of Transport Geography, 19, 11981209.

Gini, C. (1913). Variabilità e mutabilità [Variability and mutability]. Journal of the Royal Statistical Society, 76, 326-327.

Hall, M. T. N. (1967) Measures of concentration. Journal of the American Statistical Association, 62, 162-168.

Hirschman, A. O. (1964) The paternity of an index. American Economic Review, 54, 761766.

Hoffman, J., \& Voss, W. (2000) Analytical identification of airport and airspace capacity constrains. $3^{\text {rd }}$ USA/Europe Air Traffic Management R\&D Seminar Napoli, June 2000.

Huber, H. (2009) Comparing spatial concentration and assessing relative market structure in air traffic. Journal of Air Transport Management, 15, 184-194.

Koo, T. T. R., \& Lohmann, G. (2013) The spatial effects of domestic aviation deregulation: a comparative study of Australian and Brazilian seat capacity, 1986-2010. Journal of Transport Geography, 29, 52-62.

Lijesen, M. G. (2004) Adjusting the Herfindahl index for close substitutes: an application to pricing in civil aviation. Transportation Research Part E: Logistics and Transportation Review, 40, 123-134.

Lohmann, G., Albers, S., Koch, B., \& Pavlovich, K. (2009) From hub to tourist destination an explorative study of Singapore and Dubai's aviation-based transformation. Journal of Air Transport Management, 15, 205-211.

Lohmann, G., \& Trischler, J. (2012) Tourism transport issues in Brazil. In: Lohmann, G. \& Dredge, D. (Eds.). Tourism in Brazil: Environment, management and segments. London and New York: Routledge, 44-59. 
Martin, J. C., \& Voltes-Dorta, A. (2009) A note on how to measure hubbing pratices in airline networks. Transportation Reasearch Part E: Logistics and Transportation Review, 45, 250-254.

Nero, G. (1999) A note on the competitive advantages of the large hub-and-spoke networks. Transportation Reasearch Part E: Logistics and Transportation Review, 35, 225-239.

Papatheodorou, A. (2009) Spatial evolution of airport traffic and air transport liberalisation: the case of Greece. Journal of Transport Geography, 17, 402-412.

Pels, E. (2001) A note on airlines alliances. Journal of Air Transport Management, 7, 3-7.

Reynolds-Feighan, A. (1998) The impact of US airline deregulation on airport traffic patterns. Geographical Analysis, 30, 234-253.

Reynolds-Feighan, A. (2001) Traffic distribution in low-cost and full-service carrier networks in the US air transportation market. Journal of Air Transport Management, $7,265-275$.

Rodrigue, J. P., Comtois, C., \& Slack, B. (ed.) (2006) The geography of transport systems, New York: Routledge.

Shaw, S. L., Lu, F., Chen, J., \& Zhou, C. (2009). China's airline consolidation and its effects on domestic airline networks and competition. Journal of Transport Geography, 17, 293305.

Whinston, M. D., \& Collins, S. C. (1992) Entry and competitive structure in deregulated airline markets: An event study analysis of People Express. RAND Journal of Economics, 23, 445-462. 


\section{Appendix}

[insert Table 4 here]

[insert Table 5 here]

[insert Table 6 here]

[insert Table 7 here] 


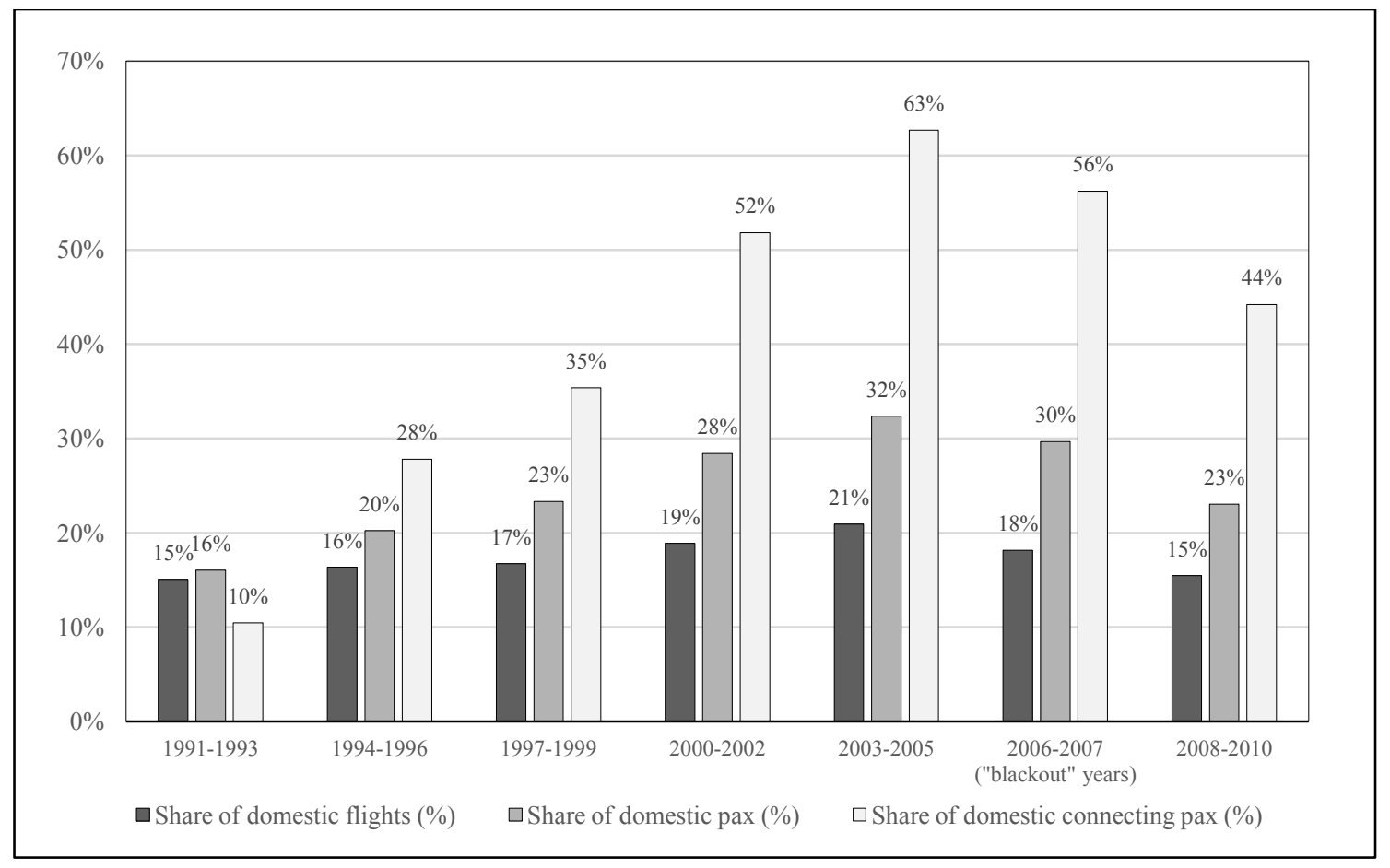

Figure 1 - Evolution of Top 2 domestic airports ${ }^{1}$

${ }^{1}$ Source: Infraero's unpublished airport operations statistics (1990-2010). 
Figure 2

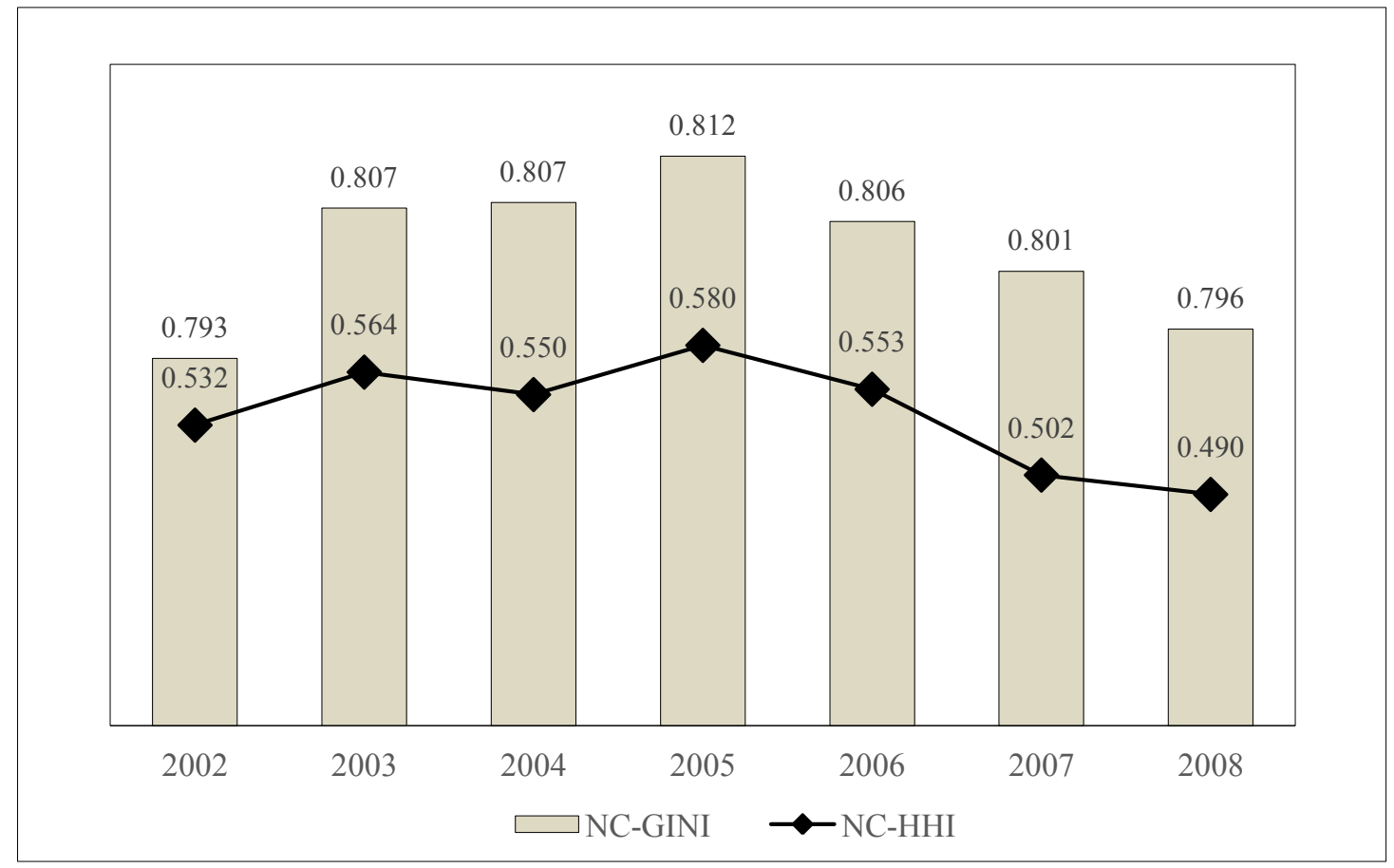

Figure 2. Evolution of network concentration - annual average ${ }^{1}$

${ }^{1}$ Source: INFRAERO's statistics with own calculations. 


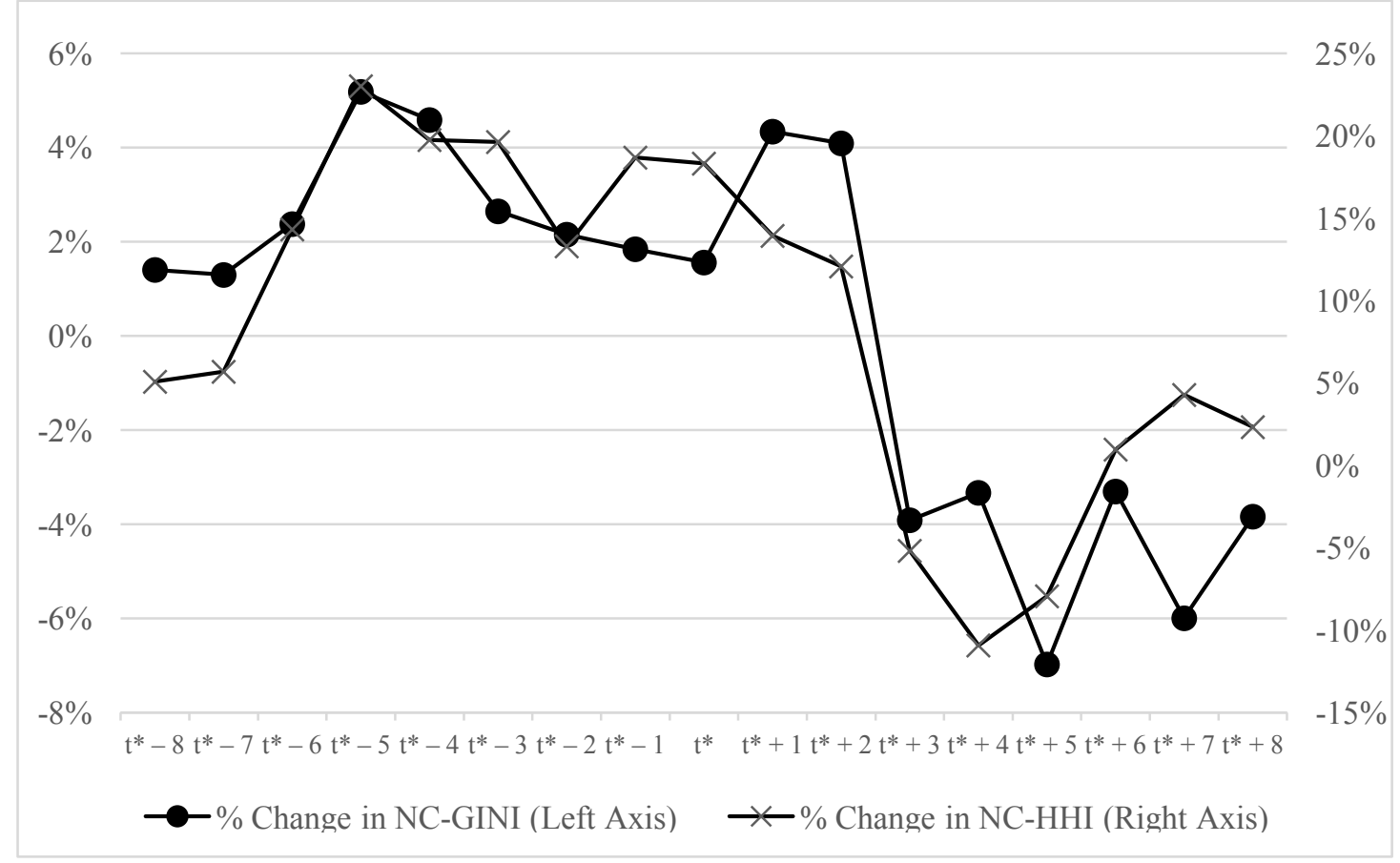

Figure 3 - Estimated changes in network concentration (\%) 
Table 1 - Evolution of flight disruptions in Brazil during the big blackout ${ }^{1}$

\begin{tabular}{cccccccc}
\hline year & $\begin{array}{c}(1) \\
\text { Domestic } \\
\text { Flights }^{\mathrm{i}}\end{array}$ & $\begin{array}{c}(2) \\
\text { Cancelled } \\
\text { Flights }^{\mathrm{i}}\end{array}$ & $\begin{array}{c}(3) \\
\text { Delayed } \\
\text { Flights }^{\text {ii }}\end{array}$ & $\begin{array}{c}(4) \\
\text { Disrupted } \\
(2)+(3)\end{array}$ & $\begin{array}{c}\% \\
\text { Cancelled } \\
(2) /(1)\end{array}$ & $\begin{array}{c}\% \\
\text { Delayed } \\
(3) /(1)\end{array}$ & $\begin{array}{c}\% \\
\text { Disrupted } \\
(4) /(1)\end{array}$ \\
\hline 2004 & 555.2 & 84.2 & 78.1 & 162.3 & $15.2 \%$ & $14.1 \%$ & $29.2 \%$ \\
2005 & 573.5 & 80.7 & 99.6 & 180.3 & $14.1 \%$ & $17.4 \%$ & $31.4 \%$ \\
2006 & 608.3 & 100.6 & 152.3 & 252.9 & $16.5 \%$ & $25.0 \%$ & $41.6 \%$ \\
2007 & 667.4 & 137.8 & 253.6 & 391.4 & $20.7 \%$ & $38.0 \%$ & $58.6 \%$ \\
2008 & 685.9 & 67.9 & 151.5 & 219.4 & $9.9 \%$ & $22.1 \%$ & $32.0 \%$ \\
2009 & 761.5 & 71.8 & 99.4 & 171.2 & $9.4 \%$ & $13.1 \%$ & $22.5 \%$ \\
2010 & 883.2 & 74.3 & 141.3 & 215.6 & $8.4 \%$ & $16.0 \%$ & $24.4 \%$ \\
\hline
\end{tabular}

i. in thousands. Source: National Agency for Civil Aviation (ANAC).

ii. in thousands. Source: National Agency for Civil Aviation (ANAC). Flights are classified as "delayed" if delay time is higher than thirty minutes.

${ }^{1}$ Source: National Agency for Civil Aviation (ANAC), delays and cancellations worksheet, available at www.anac.gov.br. 
Table 2 - Descriptive statistics of continuous variables

\begin{tabular}{lccccc}
\hline \multicolumn{1}{c}{ Variable } & Unity & Mean & Std.Dev. & Min. & Max. \\
\hline$N C_{\text {GINI }}$ & index [0,1] & 0.80 & 0.01 & 0.78 & 0.81 \\
$N C_{H H I}$ & index [0,1] & 0.53 & 0.05 & 0.41 & 0.62 \\
domestic pax & million pax & 7.63 & 2.11 & 4.96 & 13.76 \\
international pax & million pax & 1.07 & 0.20 & 0.70 & 1.59 \\
effective competitors & inv(index [0,1]) & 5.11 & 0.42 & 4.15 & 5.87 \\
jet fuel price & USD per gallon & 3.20 & 0.82 & 1.31 & 5.07 \\
\hline
\end{tabular}


Table 3 - Estimation results (2SGMM) ${ }^{1}$

\begin{tabular}{|c|c|c|c|c|c|c|}
\hline & $\begin{array}{c}(1) \\
\lg (\mathrm{NC}-\mathrm{GINI})\end{array}$ & $\begin{array}{c}(2) \\
\lg (\mathrm{NC}-\mathrm{GINI})\end{array}$ & $\begin{array}{c}(3) \\
\lg (\mathrm{NC}-\mathrm{GINI})\end{array}$ & $\begin{array}{c}(4) \\
\lg (\mathrm{NC}-\mathrm{HHI})\end{array}$ & $\begin{array}{c}(5) \\
\lg (\mathrm{NC}-\mathrm{HHI})\end{array}$ & $\begin{array}{c}(6) \\
\lg (\mathrm{NC}-\mathrm{HHI})\end{array}$ \\
\hline domestic pax & -0.0217 & $-0.0379 * * *$ & $-0.0413 * * *$ & $-0.0929 *$ & $-0.0654 *$ & $-0.0733 * * *$ \\
\hline international pax & 0.0861 & $0.1906^{* *}$ & $0.2406^{* *}$ & $0.7111 *$ & $0.4976^{* *}$ & $0.6038 * * *$ \\
\hline jet fuel price & $0.0173 *$ & 0.0026 & 0.0040 & -0.0153 & 0.0182 & -0.0026 \\
\hline effective carriers & -0.0308 & -0.0081 & -0.0006 & -0.2257 & -0.0212 & -0.0532 \\
\hline blackout - before & & $0.0301 * * *$ & & & $0.1508 * * *$ & \\
\hline blackout - during & $0.0324 * * *$ & $0.0325 * * *$ & & $0.1088 * * *$ & $0.1558 * * *$ & \\
\hline blackout - after & & $-0.0445 * * *$ & & & -0.0294 & \\
\hline blackout t* - 8 & & & 0.0140 & & & $0.0508 * *$ \\
\hline blackout t* -7 & & & 0.0129 & & & 0.0568 \\
\hline blackout $t^{*}-6$ & & & $0.0237 * *$ & & & $0.1431 * * *$ \\
\hline blackout $t^{*}-5$ & & & $0.0518 * * *$ & & & $0.2300 * * *$ \\
\hline blackout $t^{*}-4$ & & & $0.0458 * * *$ & & & $0.1974 * * *$ \\
\hline blackout $t^{*}-3$ & & & 0.0264 & & & $0.1962 * * *$ \\
\hline blackout $t^{*}-2$ & & & $0.0215^{* *}$ & & & $0.1329 * * *$ \\
\hline blackout $t^{*}-1$ & & & $0.0184 * *$ & & & $0.1867 * * *$ \\
\hline blackout $\mathrm{t}^{*}$ & & & $0.0156^{*}$ & & & $0.1831 * * *$ \\
\hline blackout $t^{*}+1$ & & & $0.0434 * * *$ & & & $0.1392 * * *$ \\
\hline blackout $\mathrm{t}^{*}+2$ & & & $0.0409 * * *$ & & & $0.1207 * * *$ \\
\hline blackout $t^{*}+3$ & & & $-0.0391 * *$ & & & -0.0518 \\
\hline blackout $t^{*}+4$ & & & $-0.0333 * * *$ & & & $-0.1092 * * *$ \\
\hline blackout $t^{*}+5$ & & & $-0.0698 * * *$ & & & $-0.0794 * * *$ \\
\hline blackout $t^{*}+6$ & & & $-0.0330 * * *$ & & & 0.0096 \\
\hline blackout $t^{*}+7$ & & & $-0.0600 * * *$ & & & 0.0427 \\
\hline blackout $t^{*}+8$ & & & $-0.0384 * * *$ & & & 0.0232 \\
\hline trend & 0.0003 & $0.0008 *$ & 0.0007 & -0.0017 & $-0.0035 * * *$ & $-0.0032 * * *$ \\
\hline dummy - February & 0.0099 & 0.0061 & 0.0083 & $0.0686^{*}$ & $0.0734 * * *$ & $0.0740 * * *$ \\
\hline dummy - March & $0.0302 *$ & $0.0325 * * *$ & $0.0355 * * *$ & $0.2009 * * *$ & $0.1785 * * *$ & $0.1838 * * *$ \\
\hline dummy - April & 0.0363 & $0.0515 * * *$ & $0.0554 * * *$ & $0.2441 * * *$ & $0.2017 * * *$ & $0.2128 * * *$ \\
\hline dummy - May & 0.0281 & $0.0506 * * *$ & $0.0576 * * *$ & $0.2921 * * *$ & $0.2435 * * *$ & $0.2570 * * *$ \\
\hline dummy - June & 0.0280 & $0.0390 * *$ & $0.0446 * * *$ & $0.2722 * * *$ & $0.2297 * * *$ & $0.2387 * * *$ \\
\hline dummy - July & -0.0005 & 0.0170 & 0.0172 & $0.1478 * *$ & $0.1258 * * *$ & $0.1088 * * *$ \\
\hline dummy - August & 0.0051 & 0.0215 & 0.0209 & $0.1795 * * *$ & $0.1855 * * *$ & $0.1681 * * *$ \\
\hline dummy - September & 0.0136 & $0.0328 *$ & $0.0363 *$ & $0.2537 * * *$ & $0.2259 * * *$ & $0.2199 * * *$ \\
\hline dummy - October & 0.0250 & $0.0435 * *$ & $0.0482 * *$ & $0.2472 * * *$ & $0.2305 * * *$ & $0.2375 * * *$ \\
\hline dummy - November & 0.0210 & $0.0359 *$ & 0.0420 & $0.2288 * * *$ & $0.2112 * * *$ & $0.2169 * * *$ \\
\hline dummy - December & -0.0039 & 0.0123 & 0.0155 & $0.1533 * * *$ & $0.1326 * * *$ & $0.1340 * * *$ \\
\hline Adj. R Squared & 0.6132 & 0.7873 & 0.8284 & 0.7565 & 0.9560 & 0.9754 \\
\hline RMSE & 0.0312 & 0.0233 & 0.0224 & 0.1138 & 0.0488 & 0.0390 \\
\hline F Statistic & 18.4892 & 52.2256 & $1.3 \mathrm{e}+03$ & 26.6246 & 329.6529 & $3.3 \mathrm{e}+03$ \\
\hline F P-Value & 0.0000 & 0.0000 & 0.0000 & 0.0000 & 0.0000 & 0.0000 \\
\hline RESET Statistic & 0.0017 & 0.3063 & 0.7189 & 0.0262 & 0.0486 & 1.0772 \\
\hline RESET P-Value & 0.9667 & 0.5799 & 0.3965 & 0.8715 & 0.8256 & 0.2993 \\
\hline KP Statistic & 6.6336 & 6.7689 & 6.9566 & 5.8281 & 6.1803 & 5.5717 \\
\hline KP P-Value & 0.0845 & 0.0796 & 0.0733 & 0.0543 & 0.0455 & 0.0617 \\
\hline J Statistic & 4.8049 & 2.6091 & 2.3283 & 0.1140 & 0.8900 & 0.2191 \\
\hline J P-Value & 0.0905 & 0.2713 & 0.3122 & 0.7356 & 0.3455 & 0.6398 \\
\hline
\end{tabular}

${ }^{1}$ Results produced by the two-step feasible efficient generalized method of moments estimator (2SGMM); statistics robust and efficient to arbitrary heteroskedasticity and autocorrelation; figures are representative of the estimated elasticities calculated at the sample mean; P-value representations: ${ }^{* *} \mathrm{p}<0.01,{ }^{* *} \mathrm{p}<0.05,{ }^{*} \mathrm{p}<0.10$; results generated by alternative estimators presented in the Appendix. 

Table 4 - Estimation results (OLS) ${ }^{1}$

\begin{tabular}{|c|c|c|c|c|c|c|}
\hline & $\begin{array}{c}(1) \\
\lg (\mathrm{NC}-\mathrm{GINI})\end{array}$ & $\begin{array}{c}(2) \\
\lg (\mathrm{NC}-\mathrm{GINI}) \\
\end{array}$ & $\begin{array}{c}(3) \\
\lg (\mathrm{NC}-\mathrm{GINI})\end{array}$ & $\begin{array}{c}(4) \\
\lg (\mathrm{NC}-\mathrm{HHI})\end{array}$ & $\begin{array}{c}(5) \\
\lg (\mathrm{NC}-\mathrm{HHI})\end{array}$ & $\begin{array}{c}(6) \\
\lg (\mathrm{NC}-\mathrm{HHI})\end{array}$ \\
\hline domestic pax & $-0.0184 * * *$ & $-0.0264 * * *$ & $-0.0245 * * *$ & $-0.0736 * * *$ & $-0.0840 * * *$ & $-0.0896 * * *$ \\
\hline international pax & $0.2179 * * *$ & $0.2150 * * *$ & $0.1990 * * *$ & $0.7801 * * *$ & $0.6637 * * *$ & $0.7169 * * *$ \\
\hline jet fuel price & $0.0234 * * *$ & $0.0140 * * *$ & $0.0176 * * *$ & $0.0539 * *$ & 0.0132 & -0.0065 \\
\hline effective carriers & -0.0065 & -0.0005 & -0.0034 & -0.0078 & 0.0022 & -0.0133 \\
\hline blackout - before & & $0.0281 * * *$ & & & $0.1433 * * *$ & \\
\hline blackout - during & $0.0432 * * *$ & $0.0403 * * *$ & & $0.1399 * * *$ & $0.1541 * * *$ & \\
\hline blackout - after & & $-0.0344 * * *$ & & & -0.0398 & \\
\hline blackout t* - 8 & & & 0.0140 & & & $0.0618 * * *$ \\
\hline blackout t* -7 & & & 0.0188 & & & $0.0636 * * *$ \\
\hline blackout t* -6 & & & $0.0166^{* *}$ & & & $0.1537 * * *$ \\
\hline blackout $\mathrm{t}^{*}-5$ & & & $0.0403 * * *$ & & & $0.2292 * * *$ \\
\hline blackout t* - 4 & & & $0.0441 * * *$ & & & $0.1981 * * *$ \\
\hline blackout $t^{*}-3$ & & & $0.0382 * * *$ & & & $0.1832 * * *$ \\
\hline blackout $t^{*}-2$ & & & $0.0246 * * *$ & & & $0.1191 * * *$ \\
\hline blackout t* - 1 & & & 0.0115 & & & $0.1880 * * *$ \\
\hline blackout $t^{*}$ & & & $0.0239 *$ & & & $0.1805 * * *$ \\
\hline blackout t* +1 & & & $0.0561 * * *$ & & & $0.1379 * * *$ \\
\hline blackout $\mathrm{t}^{*}+2$ & & & $0.0384 * * *$ & & & $0.1328 * * *$ \\
\hline blackout $t^{*}+3$ & & & -0.0172 & & & $-0.0696 * *$ \\
\hline blackout $\mathrm{t}^{*}+4$ & & & $-0.0235^{*}$ & & & $-0.1092 * * *$ \\
\hline blackout $t^{*}+5$ & & & $-0.0530 * * *$ & & & $-0.0844 * * *$ \\
\hline blackout $\mathrm{t}^{*}+6$ & & & $-0.0398 * * *$ & & & 0.0167 \\
\hline blackout $t^{*}+7$ & & & $-0.0477 * * *$ & & & 0.0225 \\
\hline blackout $\mathrm{t}^{*}+8$ & & & $-0.0286^{*}$ & & & 0.0192 \\
\hline trend & $-0.0007 *$ & -0.0001 & -0.0001 & $-0.0048 * * *$ & $-0.0032 * * *$ & $-0.0029 * * *$ \\
\hline dummy - February & $0.0338 * * *$ & $0.0221 * * *$ & $0.0224 * * *$ & $0.1025 * * *$ & $0.0692 * * *$ & $0.0697 * * *$ \\
\hline dummy - March & $0.0489 * * *$ & $0.0415 * * *$ & $0.0412 * * *$ & $0.2044 * * *$ & $0.1797 * * *$ & $0.1839 * * *$ \\
\hline dummy - April & $0.0697 * * *$ & $0.0623 * * *$ & $0.0619 * * *$ & $0.2625 * * *$ & $0.2257 * * *$ & $0.2248 * * *$ \\
\hline dummy - May & $0.0697 * * *$ & $0.0623 * * *$ & $0.0612 * * *$ & $0.3170 * * *$ & $0.2742 * * *$ & $0.2753 * * *$ \\
\hline dummy - June & $0.0638 * * *$ & $0.0554 * * *$ & $0.0549 * * *$ & $0.2941 * * *$ & $0.2530 * * *$ & $0.2523 * * *$ \\
\hline dummy - July & 0.0106 & $0.0159 *$ & 0.0138 & $0.1333 * * *$ & $0.1390 * * *$ & $0.1242 * * *$ \\
\hline dummy - August & $0.0308 * *$ & $0.0294 * *$ & $0.0276^{*}$ & $0.2040 * * *$ & $0.1947 * * *$ & $0.1782 * * *$ \\
\hline dummy - September & $0.0455 * * *$ & $0.0432 * * *$ & $0.0401 * * *$ & $0.2613 * * *$ & $0.2436 * * *$ & $0.2342 * * *$ \\
\hline dummy - October & $0.0502 * * *$ & $0.0504 * * *$ & $0.0471 * *$ & $0.2674 * * *$ & $0.2507 * * *$ & $0.2537 * * *$ \\
\hline dummy - November & $0.0553 * * *$ & $0.0506 * * *$ & $0.0481 * *$ & $0.2609 * * *$ & $0.2295 * * *$ & $0.2294 * * *$ \\
\hline dummy - December & 0.0183 & 0.0175 & 0.0160 & $0.1617 * * *$ & $0.1452 * * *$ & $0.1420 * * *$ \\
\hline Adj. R Squared & 0.7211 & 0.8351 & 0.8614 & 0.9011 & 0.9583 & 0.9773 \\
\hline RMSE & 0.0265 & 0.0205 & 0.0201 & 0.0722 & 0.0473 & 0.0373 \\
\hline F Statistic & 73.3327 & 102.3885 & $1.2 \mathrm{e}+03$ & 111.0812 & 223.8563 & $4.1 \mathrm{e}+03$ \\
\hline F P-Value & 0.0000 & 0.0000 & 0.0000 & 0.0000 & 0.0000 & 0.0000 \\
\hline RESET Statistic & 0.4622 & 0.0218 & 0.0177 & 0.3150 & 2.6491 & 17.2878 \\
\hline RESET P-Value & 0.4966 & 0.8827 & 0.8942 & 0.5746 & 0.1036 & 0.0000 \\
\hline
\end{tabular}

\footnotetext{
${ }^{1}$ Results produced by the ordinary least squares estimator (OLS); statistics robust to arbitrary heteroskedasticity and autocorrelation; figures are representative of the estimated elasticities calculated at the sample mean; P-value representations: ${ }^{* * *} \mathrm{p}<0.01,{ }^{* *} \mathrm{p}<0.05,{ }^{*} \mathrm{p}<0.10$.
} 
Table 5 - Estimation results with omitted domestic pax (2SGMM) ${ }^{1}$

\begin{tabular}{|c|c|c|c|c|c|c|}
\hline & $\begin{array}{c}(1) \\
\lg (\mathrm{NC}-\mathrm{GINI})\end{array}$ & $\begin{array}{c}(2) \\
\lg (\mathrm{NC}-\mathrm{GINI})\end{array}$ & $\begin{array}{c}(3) \\
\lg (\mathrm{NC}-\mathrm{GINI})\end{array}$ & $\begin{array}{c}(4) \\
\lg (\mathrm{NC}-\mathrm{HHI}) \\
\end{array}$ & $\begin{array}{c}(5) \\
\lg (\mathrm{NC}-\mathrm{HHI}) \\
\end{array}$ & $\begin{array}{c}(6) \\
\lg (\mathrm{NC}-\mathrm{HHI}) \\
\end{array}$ \\
\hline \multicolumn{7}{|l|}{ domestic pax } \\
\hline international pax & -0.0497 & -0.0111 & -0.0378 & 0.1286 & 0.0736 & 0.1229 \\
\hline jet fuel price & $0.0201 * *$ & $0.0139 *$ & $0.0264 * * *$ & 0.0426 & $0.0546 * * *$ & $0.0292 *$ \\
\hline effective carriers & $-0.0779 * * *$ & $-0.0605 * * *$ & $-0.0417 * * *$ & -0.3005 & $-0.0801 *$ & $-0.1347 * * *$ \\
\hline blackout - before & & $0.0372 * * *$ & & & $0.1643 * * *$ & \\
\hline blackout - during & $0.0301 * * *$ & $0.0384 * * *$ & & $0.1113 * * *$ & $0.1603 * * *$ & \\
\hline blackout - after & & $-0.0242 * *$ & & & 0.0042 & \\
\hline blackout $t^{*}-8$ & & & 0.0165 & & & $0.0605 * *$ \\
\hline blackout $t^{*}-7$ & & & $0.0384 * * *$ & & & $0.0920 *$ \\
\hline blackout $t^{*}-6$ & & & $0.0177 *$ & & & $0.1376^{* * *}$ \\
\hline blackout $t^{*}-5$ & & & $0.0500^{* * *}$ & & & $0.2370 * * *$ \\
\hline blackout $t^{*}-4$ & & & $0.0526^{* * *}$ & & & $0.2170 * * *$ \\
\hline blackout $t^{*}-3$ & & & $0.0740^{* * *}$ & & & $0.2701 * * *$ \\
\hline blackout $t^{*}-2$ & & & $0.0484 * * *$ & & & $0.1846 * * *$ \\
\hline blackout $t^{*}-1$ & & & 0.0001 & & & $0.1670 * * *$ \\
\hline blackout t* & & & $0.0269^{* * *}$ & & & $0.2090 * * *$ \\
\hline blackout $t^{*}+1$ & & & $0.0687 * * *$ & & & $0.1734 * * *$ \\
\hline blackout $t^{*}+2$ & & & $0.0229^{* *}$ & & & $0.0886^{* * *}$ \\
\hline blackout $t^{*}+3$ & & & 0.0110 & & & $0.0415^{*}$ \\
\hline blackout $t^{*}+4$ & & & $-0.0183 *$ & & & $-0.0808 * * *$ \\
\hline blackout $t^{*}+5$ & & & $-0.0323 * * *$ & & & -0.0236 \\
\hline blackout $t^{*}+6$ & & & $-0.0524 * * *$ & & & -0.0151 \\
\hline blackout $t^{*}+7$ & & & -0.0167 & & & $0.1314 * * *$ \\
\hline blackout $t^{*}+8$ & & & $-0.0286^{* *}$ & & & $0.0547 *$ \\
\hline trend & -0.0001 & -0.0002 & -0.0004 & $-0.0046^{* * *}$ & $-0.0053^{* * *}$ & $-0.0051^{* * *}$ \\
\hline dummy - February & 0.0162 & $0.0194 *$ & $0.0174 *$ & $0.0978 * *$ & $0.0897 * * *$ & $0.0982 * * *$ \\
\hline dummy - March & $0.0294 *$ & $0.0309^{* * *}$ & $0.0302 * * *$ & $0.1940 * * *$ & $0.1731 * * *$ & $0.1792 * * *$ \\
\hline dummy - April & 0.0180 & 0.0220 & $0.0311^{* *}$ & $0.1655^{* *}$ & $0.1477 * * *$ & $0.1705^{* * *}$ \\
\hline dummy - May & 0.0059 & 0.0131 & 0.0180 & $0.1931 * *$ & $0.1558 * * *$ & $0.1870^{* * *}$ \\
\hline dummy - June & 0.0090 & 0.0133 & 0.0191 & $0.1782 * *$ & $0.1502 * * *$ & $0.1740 * * *$ \\
\hline dummy - July & -0.0112 & -0.0048 & -0.0071 & 0.0729 & $0.0674 * * *$ & $0.0512 * *$ \\
\hline dummy - August & 0.0015 & 0.0088 & 0.0075 & $0.1583 * * *$ & $0.1579 * * *$ & $0.1383^{* * *}$ \\
\hline dummy - September & 0.0044 & 0.0163 & 0.0068 & $0.1901 * * *$ & $0.1712 * * *$ & $0.1626^{* * *}$ \\
\hline dummy - October & 0.0073 & 0.0129 & 0.0110 & $0.1591 * * *$ & $0.1494 * * *$ & $0.1674 * * *$ \\
\hline dummy - November & 0.0074 & 0.0171 & 0.0171 & $0.1695^{* * *}$ & $0.1468 * * *$ & $0.1619 * * *$ \\
\hline dummy - December & -0.0124 & -0.0049 & 0.0010 & $0.1026^{* * *}$ & $0.0881^{* * *}$ & $0.0964 * * *$ \\
\hline Adj. R Squared & 0.4988 & 0.7015 & 0.7981 & 0.7559 & 0.9226 & 0.9528 \\
\hline RMSE & 0.0354 & 0.0275 & 0.0242 & 0.1135 & 0.0644 & 0.0538 \\
\hline F Statistic & 17.8241 & 34.1262 & 406.3576 & 19.5635 & 182.7125 & $1.7 \mathrm{e}+03$ \\
\hline F P-Value & 0.0000 & 0.0000 & 0.0000 & 0.0000 & 0.0000 & 0.0000 \\
\hline RESET Statistic & 1.6831 & 0.3902 & 0.0006 & 0.9954 & 1.7257 & 0.0011 \\
\hline RESET P-Value & 0.1945 & 0.5322 & 0.9799 & 0.3184 & 0.1890 & 0.9736 \\
\hline KP Statistic & 4.7019 & 5.0487 & 5.7783 & 4.9751 & 5.3683 & 5.7945 \\
\hline KP P-Value & 0.3193 & 0.2823 & 0.2163 & 0.1736 & 0.1467 & 0.1220 \\
\hline J Statistic & 5.8925 & 6.6309 & 6.1659 & 2.1635 & 2.9120 & 3.1420 \\
\hline J P-Value & 0.1170 & 0.0846 & 0.1038 & 0.3390 & 0.2332 & 0.2078 \\
\hline
\end{tabular}

\footnotetext{
${ }^{1}$ Results produced by the two-step feasible efficient generalized method of moments estimator (2SGMM); statistics robust and efficient to arbitrary heteroskedasticity and autocorrelation; figures are representative of the estimated elasticities calculated at the sample mean; P-value representations: ${ }^{* * *} \mathrm{p}<0.01,{ }^{* *} \mathrm{p}<0.05,{ }^{*} \mathrm{p}<0.10$; results generated by alternative estimators presented in the Appendix.
} 
Table 6 - Estimation results (2SLS) ${ }^{1}$

\begin{tabular}{|c|c|c|c|c|c|c|}
\hline & $\begin{array}{c}(1) \\
\lg (\mathrm{NC}-\mathrm{GINI})\end{array}$ & $\begin{array}{c}(2) \\
\lg (\mathrm{NC}-\mathrm{GINI})\end{array}$ & $\begin{array}{c}(3) \\
\lg (\mathrm{NC}-\mathrm{GINI})\end{array}$ & $\begin{array}{c}(4) \\
\lg (\mathrm{NC}-\mathrm{HHI})\end{array}$ & $\begin{array}{c}(5) \\
\lg (\mathrm{NC}-\mathrm{HHI})\end{array}$ & $\begin{array}{c}(6) \\
\lg (\mathrm{NC}-\mathrm{HHI})\end{array}$ \\
\hline domestic pax & -0.0056 & $-0.0406 * * *$ & $-0.0406^{* * *}$ & -0.0787 & $-0.0646^{*}$ & $-0.0738 * * *$ \\
\hline international pax & -0.0013 & $0.2290 * * *$ & $0.2450 * * *$ & 0.6225 & $0.5212 * *$ & $0.6126 * * *$ \\
\hline jet fuel price & $0.0189 * *$ & 0.0056 & 0.0077 & -0.0088 & 0.0206 & -0.0031 \\
\hline effective carriers & -0.0694 & 0.0049 & 0.0076 & -0.2367 & -0.0213 & -0.0510 \\
\hline blackout - before & & $0.0293 * * *$ & & & $0.1494 * * *$ & \\
\hline blackout - during & $0.0332 * * *$ & $0.0362 * * *$ & & $0.1099 * * *$ & $0.1557 * * *$ & \\
\hline blackout - after & & $-0.0435 * * *$ & & & -0.0289 & \\
\hline blackout t* - 8 & & & 0.0161 & & & $0.0520 * *$ \\
\hline blackout t* - 7 & & & 0.0183 & & & 0.0576 \\
\hline blackout $t^{*}-6$ & & & $0.0250 * *$ & & & $0.1428 * * *$ \\
\hline blackout $t^{*}-5$ & & & $0.0468 * * *$ & & & $0.2298 * * *$ \\
\hline blackout $t^{*}-4$ & & & $0.0455 * * *$ & & & $0.1979 * * *$ \\
\hline blackout $t^{*}-3$ & & & 0.0297 & & & $0.1955 * * *$ \\
\hline blackout $t^{*}-2$ & & & $0.0212 *$ & & & $0.1308 * * *$ \\
\hline blackout $t^{*}-1$ & & & 0.0137 & & & $0.1872 * * *$ \\
\hline blackout $\mathrm{t}^{*}$ & & & 0.0167 & & & $0.1839 * * *$ \\
\hline blackout t* +1 & & & $0.0491 * * *$ & & & $0.1392 * * *$ \\
\hline blackout $t^{*}+2$ & & & $0.0445 * * *$ & & & $0.1202 * * *$ \\
\hline blackout $t^{*}+3$ & & & $-0.0388 * *$ & & & -0.0521 \\
\hline blackout $t^{*}+4$ & & & $-0.0299 * * *$ & & & $-0.1091 * * *$ \\
\hline blackout $t^{*}+5$ & & & $-0.0636 * * *$ & & & $-0.0794 * * *$ \\
\hline blackout $t^{*}+6$ & & & $-0.0323 * * *$ & & & 0.0090 \\
\hline blackout t* +7 & & & $-0.0630 * * *$ & & & 0.0418 \\
\hline blackout $t^{*}+8$ & & & $-0.0371 * *$ & & & 0.0241 \\
\hline trend & -0.0001 & 0.0007 & 0.0006 & -0.0022 & $-0.0036 * * *$ & $-0.0032 * * *$ \\
\hline dummy - February & 0.0159 & 0.0046 & 0.0071 & $0.0733 *$ & $0.0757 * * *$ & $0.0751 * * *$ \\
\hline dummy - March & $0.0320 *$ & $0.0317 * * *$ & $0.0337 * * *$ & $0.1973 * * *$ & $0.1792 * * *$ & $0.1846^{* * *}$ \\
\hline dummy - April & 0.0266 & $0.0545 * * *$ & $0.0560 * * *$ & $0.2327 * * *$ & $0.2085 * * *$ & $0.2156 * * *$ \\
\hline dummy - May & 0.0164 & $0.0558 * * *$ & $0.0580 * * *$ & $0.2793 * * *$ & $0.2499 * * *$ & $0.2608 * * *$ \\
\hline dummy - June & 0.0175 & $0.0466 * * *$ & $0.0484 * * *$ & $0.2599 * * *$ & $0.2347 * * *$ & $0.2424 * * *$ \\
\hline dummy - July & -0.0075 & $0.0213 *$ & 0.0214 & $0.1389 *$ & $0.1257 * * *$ & $0.1118 * * *$ \\
\hline dummy - August & 0.0047 & 0.0240 & 0.0253 & $0.1797 * * *$ & $0.1870 * * *$ & $0.1697 * * *$ \\
\hline dummy - September & 0.0075 & $0.0375 * *$ & $0.0398 * *$ & $0.2476 * * *$ & $0.2271 * * *$ & $0.2214 * * *$ \\
\hline dummy - October & 0.0090 & $0.0495 * * *$ & $0.0504 * *$ & $0.2360 * * *$ & $0.2298 * * *$ & $0.2387 * * *$ \\
\hline dummy - November & 0.0132 & $0.0432 * *$ & $0.0449 *$ & $0.2201 * * *$ & $0.2133 * * *$ & $0.2189 * * *$ \\
\hline dummy - December & -0.0057 & 0.0160 & 0.0160 & $0.1456^{* * *}$ & $0.1344 * * *$ & $0.1352 * * *$ \\
\hline Adj. R Squared & 0.5520 & 0.8032 & 0.8394 & 0.7635 & 0.9564 & 0.9756 \\
\hline RMSE & 0.0336 & 0.0225 & 0.0217 & 0.1122 & 0.0486 & 0.0389 \\
\hline F Statistic & 18.3881 & 51.8105 & $1.3 \mathrm{e}+03$ & 25.1504 & 307.8307 & $3.0 \mathrm{e}+03$ \\
\hline F P-Value & 0.0000 & 0.0000 & 0.0000 & 0.0000 & 0.0000 & 0.0000 \\
\hline RESET Statistic & 0.8403 & 0.2957 & 0.8536 & 0.0529 & 0.0260 & 1.1397 \\
\hline RESET P-Value & 0.3593 & 0.5866 & 0.3555 & 0.8182 & 0.8718 & 0.2857 \\
\hline KP Statistic & 6.6336 & 6.7689 & 6.9566 & 5.8281 & 6.1803 & 5.5717 \\
\hline KP P-Value & 0.0845 & 0.0796 & 0.0733 & 0.0543 & 0.0455 & 0.0617 \\
\hline J Statistic & 4.8049 & 2.6091 & 2.3283 & 0.1140 & 0.8900 & 0.2191 \\
\hline J P-Value & 0.0905 & 0.2713 & 0.3122 & 0.7356 & 0.3455 & 0.6398 \\
\hline
\end{tabular}

\footnotetext{
${ }^{1}$ Results produced by the two-stage least squares estimator (2SLS); statistics robust to arbitrary heteroskedasticity and autocorrelation; figures are representative of the estimated elasticities calculated at the sample mean; P-value representations: ${ }^{* * *} \mathrm{p}<0.01,{ }^{* *} \mathrm{p}<0.05,{ }^{*} \mathrm{p}<0.10$.
} 
Table 7 - Estimation results (LIML) ${ }^{1}$

\begin{tabular}{|c|c|c|c|c|c|c|}
\hline & $\begin{array}{c}(1) \\
\lg (\mathrm{NC}-\mathrm{GINI})\end{array}$ & $\begin{array}{c}(2) \\
\lg (\mathrm{NC}-\mathrm{GINI}) \\
\end{array}$ & $\begin{array}{c}(3) \\
\lg (\mathrm{NC}-\mathrm{GINI}) \\
\end{array}$ & $\begin{array}{c}(4) \\
\lg (\mathrm{NC}-\mathrm{HHI})\end{array}$ & $\begin{array}{c}(5) \\
\lg (\mathrm{NC}-\mathrm{HHI})\end{array}$ & $\begin{array}{c}(6) \\
\lg (\mathrm{NC}-\mathrm{HHI})\end{array}$ \\
\hline domestic pax & -0.0056 & $-0.0406 * * *$ & $-0.0406 * * *$ & -0.0787 & $-0.0646^{*}$ & $-0.0738 * * *$ \\
\hline international pax & -0.0013 & $0.2290 * * *$ & $0.2450 * * *$ & 0.6225 & $0.5212 * *$ & $0.6126 * * *$ \\
\hline jet fuel price & $0.0189 * *$ & 0.0056 & 0.0077 & -0.0088 & 0.0206 & -0.0031 \\
\hline effective carriers & -0.0694 & 0.0049 & 0.0076 & -0.2367 & -0.0213 & -0.0510 \\
\hline blackout - before & & $0.0293 * * *$ & & & $0.1494 * * *$ & \\
\hline blackout - during & $0.0332 * * *$ & $0.0362 * * *$ & & $0.1099 * * *$ & $0.1557 * * *$ & \\
\hline blackout - after & & $-0.0435 * * *$ & & & -0.0289 & \\
\hline blackout t* - 8 & & & 0.0161 & & & $0.0520 * *$ \\
\hline blackout $t^{*}-7$ & & & 0.0183 & & & 0.0576 \\
\hline blackout t* - 6 & & & $0.0250 * *$ & & & $0.1428 * * *$ \\
\hline blackout $t^{*}-5$ & & & $0.0468 * * *$ & & & $0.2298 * * *$ \\
\hline blackout $t^{*}-4$ & & & $0.0455 * * *$ & & & $0.1979 * * *$ \\
\hline blackout $\mathrm{t}^{*}-3$ & & & 0.0297 & & & $0.1955 * * *$ \\
\hline blackout $\mathrm{t}^{*}-2$ & & & $0.0212 *$ & & & $0.1308 * * *$ \\
\hline blackout $t^{*}-1$ & & & 0.0137 & & & $0.1872 * * *$ \\
\hline blackout $\mathrm{t}^{*}$ & & & 0.0167 & & & $0.1839 * * *$ \\
\hline blackout $t^{*}+1$ & & & $0.0491 * * *$ & & & $0.1392 * * *$ \\
\hline blackout $t^{*}+2$ & & & $0.0445 * * *$ & & & $0.1202 * * *$ \\
\hline blackout $\mathrm{t}^{*}+3$ & & & $-0.0388 * *$ & & & -0.0521 \\
\hline blackout $\mathrm{t}^{*}+4$ & & & $-0.0299 * * *$ & & & $-0.1091 * * *$ \\
\hline blackout $\mathrm{t}^{*}+5$ & & & $-0.0636 * * *$ & & & $-0.0794 * * *$ \\
\hline blackout $\mathrm{t}^{*}+6$ & & & $-0.0323 * * *$ & & & 0.0090 \\
\hline blackout $\mathrm{t}^{*}+7$ & & & $-0.0630 * * *$ & & & 0.0418 \\
\hline blackout $\mathrm{t}^{*}+8$ & & & $-0.0371 * *$ & & & 0.0241 \\
\hline trend & -0.0001 & 0.0007 & 0.0006 & -0.0022 & $-0.0036 * * *$ & $-0.0032 * * *$ \\
\hline dummy - February & 0.0159 & 0.0046 & 0.0071 & $0.0733 *$ & $0.0757 * * *$ & $0.0751 * * *$ \\
\hline dummy - March & $0.0320 *$ & $0.0317 * * *$ & $0.0337 * * *$ & $0.1973 * * *$ & $0.1792 * * *$ & $0.1846 * * *$ \\
\hline dummy - April & 0.0266 & $0.0545 * * *$ & $0.0560 * * *$ & $0.2327 * * *$ & $0.2085 * * *$ & $0.2156 * * *$ \\
\hline dummy - May & 0.0164 & $0.0558 * * *$ & $0.0580 * * *$ & $0.2793 * * *$ & $0.2499 * * *$ & $0.2608 * * *$ \\
\hline dummy - June & 0.0175 & $0.0466 * * *$ & $0.0484 * * *$ & $0.2599 * * *$ & $0.2347 * * *$ & $0.2424 * * *$ \\
\hline dummy - July & -0.0075 & $0.0213 *$ & 0.0214 & $0.1389 *$ & $0.1257 * * *$ & $0.1118 * * *$ \\
\hline dummy - August & 0.0047 & 0.0240 & 0.0253 & $0.1797 * * *$ & $0.1870 * * *$ & $0.1697 * * *$ \\
\hline dummy - September & 0.0075 & $0.0375 * *$ & $0.0398 * *$ & $0.2476 * * *$ & $0.2271 * * *$ & $0.2214 * * *$ \\
\hline dummy - October & 0.0090 & $0.0495 * * *$ & $0.0504 * *$ & $0.2360 * * *$ & $0.2298 * * *$ & $0.2387 * * *$ \\
\hline dummy - November & 0.0132 & $0.0432 * *$ & $0.0449 *$ & $0.2201 * * *$ & $0.2133 * * *$ & $0.2189 * * *$ \\
\hline dummy - December & -0.0057 & 0.0160 & 0.0160 & $0.1456 * * *$ & $0.1344 * * *$ & $0.1352 * * *$ \\
\hline Adj. R Squared & 0.5520 & 0.8032 & 0.8394 & 0.7635 & 0.9564 & 0.9756 \\
\hline RMSE & 0.0336 & 0.0225 & 0.0217 & 0.1122 & 0.0486 & 0.0389 \\
\hline F Statistic & 18.3881 & 51.8105 & $1.3 e+03$ & 25.1504 & 307.8307 & $3.0 \mathrm{e}+03$ \\
\hline F P-Value & 0.0000 & 0.0000 & 0.0000 & 0.0000 & 0.0000 & 0.0000 \\
\hline RESET Statistic & 0.8403 & 0.2957 & 0.8536 & 0.0529 & 0.0260 & 1.1397 \\
\hline RESET P-Value & 0.3593 & 0.5866 & 0.3555 & 0.8182 & 0.8718 & 0.2857 \\
\hline KP Statistic & 6.6336 & 6.7689 & 6.9566 & 5.8281 & 6.1803 & 5.5717 \\
\hline KP P-Value & 0.0845 & 0.0796 & 0.0733 & 0.0543 & 0.0455 & 0.0617 \\
\hline J Statistic & 4.8049 & 2.6091 & 2.3283 & 0.1140 & 0.8900 & 0.2191 \\
\hline J P-Value & 0.0905 & 0.2713 & 0.3122 & 0.7356 & 0.3455 & 0.6398 \\
\hline
\end{tabular}

${ }^{1}$ Results produced by the limited-information maximum likelihood estimator (LIML); statistics robust to arbitrary heteroskedasticity and autocorrelation; figures are representative of the estimated elasticities calculated at the sample mean; P-value representations: ${ }^{* * *} \mathrm{p}<0.01,{ }^{* *} \mathrm{p}<0.05$, $* \mathrm{p}<0.10$. 